\title{
Reading, Writing, Reasoning: A model for their integration
}

\author{
LENORE LANGSDORF University of Texas at Arlington
}

One of the distinguishing characteristics of the contemporary "critical thinking movement" is a shift of attention from brief texts devised as illustrations of logical structures to longer texts culled from journalistic and literary sources. At UTA we have extended this tendency by means of a project, funded by the NEH and planned by an interdepartmental and interinstitutional committee, which teaches critical thinking within the required sequence of English literature and composition courses. ${ }^{1}$

In this paper I attend, primarily, to the theoretical rationale for this integrated approach to the teaching of reading, writing, and reasoning. However, I also discuss the historical precedent for the conception, note the texts we use, and indicate the goals of the project. A basic aspect of the theoretical rationale is the issue of just what variety of critical thinking underlies the "reasoning" component. Accordingly, I begin with a discussion of four models which I see as options for teaching critical thinking.

Several writers have noted a sequence of developmental stages toward what now appears as a "critical thinking movement." In some surveys, 1 sense that the writer sees a linear progression, such that the earlier-to-develop varieties have been surpassed by improved later models. I do not myself see the various approaches as being better or inferior, but rather, as suited to different goals. In fact, the four models I identifyintroductory logic, practical logic, reasoning, and strong sense critical thinking-have developed in that order, and to some degree, the later ones developed from the earlier ones. ${ }^{2}$ But they are all widely used, now, and there seems no reason for one or more of them to dominate the field-or at least, not unless a consensus arises as to just what we want to accomplish in our critical thinking classrooms.

The "introductory logic model" focuses on basic concepts and techniques of formal logic (e.g. induction, deduction, forms and procedures for syllogistic and propositional logic). These are taught abstractly; i.e. either in symbolic form or through decontextualized examples devised to illustrate a particular form. Although some consideration of informal fallacies often is included, this is limited to a small group which usually are identified by their Latin names. The implication is that good argument fits the formal patterns, or can be reformulated without loss of essential sense so as to fit Aristotelian or Fregean patterns. Correlatively, poor arguments are those which can't be restated in a standard form, as well as those which rely on fallacies.

A paradigm textbook for this model would be Irving M. Copi's Introduction to Logic.

The "practical logic model" emphasizes developing skills in the service of "clear thinking." Usually this means a stress on identifying fallacies-often, in real or realistic examples. This attention to real-life situations sometimes involves analysis of semi-argumentive passages, such as those in advertisements. These texts can be analyzed to determine whether any reasons are offered, and if so, whether those qualify as "good reasons." Those which don't offer reasons usually offer good opportunities for identification of fallacies. A second 
major theme is reconstructing "in-

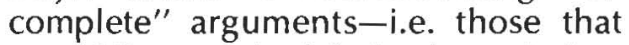
would fit a standard deductive or inductive form if implicit claims ("missing premises") were supplied.

A paradigm textbook for this model would be Ralph $\mathrm{H}$. Johnson and J. Anthony Blair's Logical Self-Defense.

The "reasoning model" focuses on the interpretation of arguments as well as on their assessment or evaluation. This first step requires a reflective and even investigative attitude toward language-one which recognizes that spoken discourse or written text may not mean only, or at all, what it first seems to mean. Also, it requires developing some sophistication and creativity about communication that isn't direct or transparent. Rather than working with an argument as given, or as reformulated to fit one or another traditional pattern, this approach looks for implicit as well as explicit good reasons for an argument's claims. Indeed, identifying and developing good reasons overshadows deciding the validity or strength or an argument.

A paradigm textbook for this model would be Michael Scriven's Reasoning.

The "critical thinking in the strong sense" $^{\prime \prime}$ model stresses comparison of the positions taken in argument as reflecting a context of interest, attitudes, and world views that are themselves the focus of criticism. In effect, this means that ideas, rather than arguments, are the focus of analysis. Reflective comparison of these, preferably in dialogue which considers the strongest versions of divergent positions, takes precedence over logical technique of any sort. Identifying and criticizing the ideas embedded in arguments requires working with themes and procedures more often associated with epistemology, metaphysics, and rhetoric-and even, psychology, hermeneutics, semiotics, and linguistics-than with logic.

A paradigm textbook for this model would be John Chaffee's Thinking Critically. ${ }^{3}$

Given this variety of models from which to choose, the first question to address in describing the project at UTA is that of goals-for very different goals are appropriately served by these different models. I'll discuss that goal by describing the problem. I'll then go on to tell of the proposal I made and the way in which we developed that proposal into a project.

The problem I experienced is one which seems to be endemic to philosophy's tenuous existence in contemporary education. As a member of a small philosophy department in a large state university, I teach a large number of undergraduate students who are not philosophy majors. Most of these students are business or engineering majors who are present in the Liberal Arts College at all only because of required courses in English and History and a less precise stipulation that they take their choice among offerings in the College for a few additional hours of "humanities." In teaching these students, I've found a rather widespread inability to understand and incorporate into their own experience the traditional texts of our cultural, and especially philosophical, heritage. Texts such as Plato's Apology, Luther's Treatise on Christian Liberty, Descartes' Discourse on Method, Mill's On Liberty, Thoreau's On Civil Disobedience, Miller's Death of a Salesman, and Camus' Myth of Sisyphus-works which I had read as an undergraduate and believed were appropriate for introductory coursesseem to be inaccessible to the majority of the students in my classes. In addition to doing my share of bemoaning this along with my colleagues, I found myself trying to understand it on some level deeper than blaming it on the vocational emphasis in contemporary education and the lack of a liberal arts tradition in our students' immediate culture.

The clue that developed into a suggestion and then into a grant proposal and a major curriculum revision came from Paul Ricoeur's text theory. ${ }^{4}$ I cannot, of course, summarize that entire 
theory here. But I will try to recount the two points that served as a clue for my understanding of the problem and suggested the nature of my response. First: In agreement with many other text theorists, Ricoeur finds a major difference between spoken and written language use. When the former, discourse, becomes the latter, text, as "distanciation" is effected which is quite obvious to all of us who both speak and read, although the implications for teaching and practicing critical thinking are not quite so obvious. ${ }^{5}$

In conversation, "missing premises" can be filled in, with at least some degree of confidence and, hopefully, a fair degree of accuracy, by interrupting the flow of dialogue toward a conclusion in order to ask just what was meant by the other speaker. In terms of the four models of critical thinking delineated at the start of this paper: the methods and techniques taught within "reasoning" and "strong sense" approaches would seem most relevant to this process, since they emphasize discovering good reasons for claims and uncovering the interest underlying an argument. Without in any way discounting the variety of conscious and unconscious factors which may limit our ability to discover a speaker's reasons, motives, and interests, we do have a means for investigating the "surplus of meaning" (to borrow Ricoeur's phrase) that informs the surface of an argument in discourse.

The situation becomes more difficult in regard to text, since the meaning of written discourse has originated at some other point in time or space. In effect, the author is unavailable; as Ricoeur puts it, the text is "autonomous." It is now available to us as an enduring objectin contrast to the fleeting event of conversation, and of discourse in general. These three features (the spatiotemporal distance of the text's origin, the unavailability of the author, and the objective status of the text) are summed up in Ricoeur's term, "distanciation." Although this situation might seem to be disadvantageous, in comparison to discourse, Ricoueur understands it simply as requiring different procedures, if meaning is to be understood and ideas and arguments are to be evaluated. Rather than ask questions in dialogue, we must interpret, and even reconstruct, the relevant contextual features (reasons, motives, and interests) in order to even understand what the text says.

All of us who have used newspaper articles and letters to the editor in teaching critical thinking know the difficulties involved in the process of coming to a fair understanding of just what those texts say-i.e., what ideas are being presented in them-even before we attempt to assess the arguments they contain. These same problems, I came to realize, are present when trying to teach the traditional humanities texts mentioned earlier. Students simply do not understand the ideas-the reasons, motives, interests, and conclusions underlying positions-presented in those "distanciated" texts.

For two reasons, the "introductory logic" and "practical logic" models are not very helpful here. First: both these models work primarily with invented or relatively simple examples devised or chosen to illustrate specific accepted or rejected patterns of argument. Thus a major question arises as to how successfully students can transfer practice with these examples into ability to understand and assess complex ideas and arguments in journalistic and literary sources. Along with many other veterans of teaching critical thinking on the basis of these models, I've concluded that there is discouragingly little transfer. Also: restating journalistic and literary texts in schematic or symbolic form presupposes that their meaning has been accurately translated, and so avoids entering into the question of whether what these texts say has been correctly, or even plausibly, understood.

The first point in Ricoeur's theory which enabled me to enter that question, then, is his conception of the 
distanciated text as requiring interpretation if what it says is to be appropriated by its readers. Interpretation is something quite distinct from restatement or reformulation, both of which are familiar to critical thinking teachers who have pondered the relative advantages of invented versus discovered (devised versus actual) arguments. There are a variety of schools of thought as to how interpretation is to be accomplished; they each recommend particular procedures and methods; they all (in my own opinion) hold out certain promises and admit of certain difficulties-which is to say that they each offer arguments, demanding our understanding and evaluation, as to the very possibility of understanding and evaluation. ${ }^{6}$ For instance, some interpretation theorists have argued that understanding a text requires understanding the author: i.e. gaining access to the psychic events in which the meaning of the text originated.

Ricoeur's theory of interpretation, based as it is in his characterization of the text as distanciated-as an autonomous object, rather than an event of any sort-rejects this psychological approach. The distanciated text, Ricoeur argues, is a special sort of object, rather than a feature of the author's psychic state. Thus the means for its appropriation are adapted from linguistics, rhetoric, and cultural studies, rather than from psychology. Therefore, if my goal is enabling students to appropriate and evaluate the ideas and arguments of those texts which have contributed to our cultural heritage-e.g. the texts named earlier-I must recognize that these texts are not immediately accessible; but neither are they as inaccessible as are the psychic events of the author's consciousness.

Once I recognize that this relative inaccessibility is due to the nature of text-rather than to pedagogical, sociological, or psychological factors-! must be prepared to embark upon what I've come to call "critical thinking readiness." This means using methods of textual analysis in order to uncover what the text says, so that evaluation of its ideas and arguments is based on an understanding for which I can give "good reasons."7 In other words: the first step in thinking critically about any text-and especially, about those real and complex texts found in everyday life as well as in the books, plays, and poems that comprise our cultural heritage-is to think critically about the nature of text.

The second point in Ricoeur's text theory which helped me to understand and respond to the problem I encountered in introductory philosophy courses is his conception of the relation of "ego" to "self." He relies upon the sense of "appropriation" just discussed when he writes:

\begin{abstract}
appropriation is the process by which the revelation of new modes of being... gives the subject new capacities for knowing himself... Thus appropriation ceases to appear as a new kind of possession... it implies instead a moment of dispossession of the narcissistic ego... I should like to contrast the self which emerges from the understanding of the text to the ego which claims to precede this understanding. It is the text, with its universal power of unveiling, which gives a self to the ego. ${ }^{8}$
\end{abstract}

Grasping this point dramatically affected my comprehension of students' difficulties in reading, as well as writing and reasoning about, journalistic and literary texts. I began to see the problem as one of bringing particular egos to these texts, but also, away from them: i.e. of finding in the text only a mirror of the ego, rather than the enlarged-even, enlightened-self of which Ricoeur speaks.

When these two points are considered together, the shape of my proposal may well seem obvious. The goal of teaching Plato's Apology, Mill's On Liberty, etc., is understanding, evaluating, and-depending on the results of that evaluation-accepting, rejecting, or suspending judgment about the ideas presented in those texts. In brief, this goal requires the appropria- 
tion of distanciated texts. The goal of that appropriation, in turn, is moving from ego to self: in more usual terms, a liberal arts education develops the dispositions and abilities needed to comprehend situations from an objective standpoint as well as from the viewpoints of others who are historically, politically, or otherwise different. ${ }^{9}$

Ricoeur's explication of understanding a text as a process of appropriation in which the ego becomes a self led me to see that the fundamental dispositions and capabilities we use in responding to arguments are no different in kindthough there may well be differences in emphasis-from those we need to respond to expository and expressive texts. When this is recognized, the typical departmentalization of encounters and methods which sets the philosophy department in charge of logic and argumentation theory, while the English department is granted composition and literary theory, appears as theoretically and pedagogically unwise. For theoretical investigation of the nature of text or its comprehension which originates within a particular discipline is unlikely to spread beyond that discipline. Thus, the wheel is reinvented from various disciplinary perspectives-which does not lead to an improved wheel unless the inventors come to realize that they are all working on a wheel, albeit of different materials. (Here logicians might recognize the form and content distinction, while literature and composition theorists might recognize genre studies.) Pedagogically, opportunities for reinforcement of learning through recursive application of procedures are sacrified.

On the basis of this description of the problems I encountered in teaching introductory philosophy courses and text theory that suggested my response, I'II now sketch the proposal I made and the project we developed from that proposal. The basic feature of the proposal is integration of instruction in composition, critical thinking, and text analysis.
This means that a sequence of courses, using Ricoeur's understanding of the nature of text as its unifying theoretical basis, was designed to teach what students previously encountered-if at all-in English department courses on composition and literature and the Philosophy department course on critical thinking.

The goal of this sequence is enabling our students to become conservative and creative critics of the ideas they encounter in reading the traditionally valued works of our culture-and, by extension, enabling them also to be discerning appreciators of contemporary cultural products. "Conservative" here means protective of the ideas and values they find viable in those works. "Creative" means innovative in applying those ideas and values to novel situations. "Critics" designates individuals able to reflect on what they read and hear so as to discern and evaluate the implicit and explicit ideas and arguments presented by text and discourse, rather than finding in those cultural products only what reflects the givens of their individual biographies.

Rather than expecting students to make an effective transition from reading and assessing simplified exercises to understanding and evaluating their cultural heritage as presented in traditionally valued texts, the courses engage students with those texts from the start. And along with reading what those works have to say and evaluating the claims they make, students apply, from the start, the techniques necessary for competency in reading comprehension and argument analysis to their own writing. The precedent for this tripartite approach is the medieval trivium, which presented the study of language arts as the development of three interrelated disciplines: grammar, logic, and rhetoric.

Grammar refers here to recognizing that meaning is carried by the structure of a sentence as well as by the structure of an entire text. In other words, the term is understood in both the sense 
familiar to most students and teachers and in the sense explored by contemporary text theorists who are especially attentive to the organizational patterns used in a particular genre. Attending to grammar in the latter sense requires that students recognize the limited value of a habit which has been amply rewarded in most of their previous classroom experience. This is reading for events: i.e. summarizing the plot must be recognized as only the first step in critical reading. (Many students do need help in doing that.) The next step is reading for structure: what forms of organization may be recognized as generating structure of ideas within the text, and how do they convey meaning?

Logic is also doubly significant. Once we recognize that there is an underlying structure of ideas along with the events which form the surface (so to speak) of a text, we can examine both structure and surface for logical force. Methods of formal and informal logical analysisfrom the syllogism to fallacy identification-are useful for this task. Indeed, once the grammar study has identified both "form" and "content," the need for both types of logic, and the use of logical techniques in the formulation as well as evaluation of points of view, positions, and arguments, is almost obvious. The second and especially important aspect of this part of the program is demonstrating that logic is a creative and positive force: it promotes effective organization of the ideas in traditional texts and in the students' own writing, rather than serving only a critical, in the negative sense of faultfinding, role.

Rhetoric extends the study beyond structure and surface to function: the usual goal of a text is communication, and the likelihood of achieving that goal is enhanced by the use of appropriate rhetorical structures. Procedures for presentation, including invention and organization, provide a completion of the trivium which is also, fitting, a going beyond the study of methods and pro- cedures into the application of these studies.

In proposing the trivium as the basic model for integrating our teaching of reading, reasoning, and writing, no quaintly traditional or cosmetically conservative touch was intended. Rather, given the intrinsic and fundamental need for interpretation that Ricoeur's text theory emphasizes, I found that the trivium provides the materials for an interpretive method. This is to say that the methods and techniques of the traditional trivium-e.g. sentence grammar, syllogistic, and expressional modes-as well as contemporary research derived from or correlative to those-e.g. text grammar, informal logic, and inventive (heuristic) procedures-provide the material for a method of interpretation that responds to Ricoeur's explication of the nature of a text and the goal of comprehension.

This proposal was developed by a committee that was interdepartmental from its beginning and soon became interinstitutional. For given the breadth of disciplinary research we wanted to call upon, and given that our students come to us directly from high school or as community college transfers, my proposal suggested teams of teachers composed of members of the English and Philosophy departments, teaching assistants from the interdisciplinary Graduate Humanities Program, and teachers from the local high school and community colleges.

The three-course sequence which developed from the deliberations of this committee during several months of intensive and extensive meetings begins with a semester in which expository texts are read, reasoned about, and written. In the second semester these three competencies are applied also to argumentive texts. In the third, self-expressive texts are added and emphasized. What I would call the epistemic movement here requires development from understanding the environment as given, and thus requiring only descrip- 
tion; to understanding it as problematic, and thus requiring argument for particular viewpoints and positions; to understanding it as the result of creative forces (e.g. natural, social, artistic, Divine) or of self-expression, and thus requiring expression of the force(s) envisioned or self projected by the writer.

An extensive booklist of works appropriate to each of these emphases was developed by the committee. However, one book which was suggested in the proposal as especially suited to multiple readings which encourage different interpretations (both within and among these emphases) was retained for that purpose. For Plato's Apology can be read and logically analyzed as expository prose, as well as written about in an expository manner. As such, it tells of (and provides opportunites for writing about) a particular political order, a significant historical figure, and some persistent conceptions of the individual in relation to the family, society, and state. The same text can then be read as argument, and the questions argued in it used as issues on which students construct arguments. It can then be read once more as expressive of the human condition or of values espoused by its author-themes which lend themselves to correlative writing by students.

As may well be evident from this description of the problem, theory, proposal, and project, this curriculum revision involved many months of consideration, deliberation, planning, and preparation. It has now been used on a partial basis for three semesters. The reading, reasoning, and writing accomplishments of the students involved have been tested, and the new sequence will be required of all students in future semesters. We recognize that these are not traditional composition, critical thinking, or literature courses; neither are they compensatory or remedial courses, any more than they are "introduction to the humanities" courses. We hope that our project's integration of several functions of such courses results in increased access to the traditional works of the liberal arts curriculum, as well as improvement in the students' own writing. ${ }^{10}$

\section{Notes}

1 The project is named CACTIP (Composition, Analysis of Texts, and Critical Thinking Integrated Project). The theoretical basis I describe here was subsequently developed-by a committee of faculty members from the English and Philosophy departments, the local school district, and the two local community college systems-into a project proposal and sequence of courses. The proposal received a $\$ 560,678$ grant from the $\mathrm{Na}$ tional Endowment for the Humanities for a three-semester period (Fall 1985-Fall 1986). The faculty committee held training workshops before startup (Summer 1985) and training institutes in the two successive summers (1986 and 1987). Beginning in the fall 1987 semester, the program will replace the previous sequence of three composition and literature courses required of all undergraduates.

2 In developing these descriptions of the models I've drawn on four sources: Ralph $\mathrm{H}$. Johnson and J. Anthony Blair, "The Recent Development of Informal Logic," in Informal Logic: The First International Symposium (Inverness, CA: Edgepress, 1980); Richard W. Paul, "The Critical Thinking Movement: An Historical Perspective," in National Forum Ixv: 2-3,32 (1985); Perry Weddle, "On Theory in Informal Logic," in Informal Logic vii: 119-126 (1985); and Trudy Govier, "Five Different Ways of Approaching the Teaching of Reasoning Skills" (unpublished).

3 The seminal text (in the broader sense of the term) is Richard Paul's 1982 article, "Teaching Critical Thinking in 
in the 'Strong Sense': A Focus on SelfDeception, World Views, and a Dialectical Mode of Analysis," Informal Logic Newsletter iv: 2-7 (1982). Reprinted in APA Newsletter on Teaching Philosophy, Spring-Summer 1986: 7-9.

The most complete source for a full explication would be: Paul Ricoeur, Hermeneutics and the Human Sciences: Essays on Language, Action, and Interpretation (Cambridge University Press, 1981). Ricoeur's Interpretation Theory: Discourse and the Surplus of Meaning (Ft. Worth, TX: Texas Christian University Press, 1976) gives a more succinct account.

5 For further discussion of these points, see my "Is Critical Thinking a Technique, or a Means of Enlightenment?" in Informal Logic vii: 1-17 (1986).

6 For a discussion of the various schools included within the hermeneutic tradition, see Ricoeur's essay, "The Task of Hermeneutics," in Hermeneutics and the Human Sciences.

7 I discuss these methods in more detail in another paper entitled "Reflection, Interpretation, and the Critical Spirit," to be read at the Fifth International Conference on Critical Thinking and Educational Reform at Sonoma State University, August 1987.

8 Paul Ricoeur, Hermeneutics and the Human Sciences pp. 192-193.

9 The limits of this paper restrict me to a statement of what deserves an argument, for the issue of just what the goal of a liberal arts education is (and/or should be) is by no means as simple as this statement would suggest. I have discussed one aspect of that issue - the role of egocentricity in relation to critical thinking - in "Egocentricity: What it is and why it matters," forthcoming in the Proceedings of the Fourth Annual Conference on Critical Thinking and
Educational Reform, to be published by Sonoma State University.

10 This is a slightly revised version of a paper presented at the Christopher Newport College 1987 conference on critical thinking. I would like to thank John Hoaglund, organizer of that conference, for his suggestion that I present the project in this way for discussion at the conference. Also, I would like to acknowledge the contributions of numerous conversations with Dean of Liberal Arts Thomas E. Porter, who directed the development and implementation of the project, and with Ralph Johnson, our critical thinking consultant.

Dr. Lenore Langsdorf, Department of Philosophy, The University of Texas at Arlington, P.O. Box 19527, Arlington, Texas 76019 